\title{
Checking the Cain Plain Subsurface Layers (South of Birjand) by Remote Sensing
}

\author{
Farnusch Hajizadeh ${ }^{1} \&$ Saeed Reza Akhondi ${ }^{2}$ \\ ${ }^{1}$ Assistant Professor, Urmia University, Iran \\ ${ }^{2}$ Graduate Student, Urmia University, Iran \\ Correspondence: Farnusch Hajizadeh, Assistant Professor, Urmia University. E-mail: \\ f.hajizadeh@mail.urmia.ac.ir
}

Received: November 23, 2015

Accepted: December 3, 2015

Online Published: January 7, 2016

doi:10.5539/mas.v10n2p109

URL: http://dx.doi.org/10.5539/mas.v10n2p109

\begin{abstract}
By processing telemetry data aquifer region were studied. Considering that in this area the importance of the geological layers have been examined, as resulting number of layers are limited to three layers (fractures, topography, lithology).The combination of less scattering layer and only through certain areas of overlap can be studied.The layers can be seen that the regions of eastern and southern plains have the most overlap and are worth exploring, but the central and western plains have minimal overlap and are sometimes exploration rank next review of the non-value are exploratory.
\end{abstract}

Keywords: Cain Plain, Subsurface Layers, Remote Sensing, South of Birjand

\section{Introduction}

The importance and role of remote sensing for environmental studies is obvious because as a superior technology to researchers in the earth sciences, including Geomorphologists raised. Features such as the nature of discrete and digital satellite data, multi-spectral data, having horizontal and vertical viewing pictures, record duplication and regular phenomena are time-series data, a wide viewing angle and macro, worldwide availability, connectivity and photo mosaic images, these images may provide access to areas difficult to reach through layers and all the benefits of geo-satellite images in the studies considered Shvnd.kar remote sensing operations is that it can be a lot of information to provide the GIS system. In other words information and field data collected by remote sensing and GIS stored in a geographic name. After geometric correction of remote sensing data may cover other geographical information (Saif \& Karegar, 2011). The great discovery of visible markers to identify and extract groundwater through conventional methods, geophysical exploration will be a little time consuming and costly. That's why the use of remote sensing and GIS data for groundwater exploration and discovery areas will be effective limit (God, 1379). Vast and inaccessible areas within a short time period, valuable instruments in achieving, reviewing and maintaining underground water resources. According to the widespread use of GIS and remote sensing in various fields of study and research play an important role in reducing costs and creating an atmosphere of understanding and schematic created to study the issue and control of the area measured by the potential for finding resources Groundwater in the area of this method has been used (Adeli et al., 2010). Groundwater exploration of various surface forms of remote sensing images is visible. Some of these problems are directly related to the groundwater such as springs, lakes, soil moisture and vegetation and some indirect strategies such as: further efforts to topography, the system of joint and fracture porosity and permeability of rock and soil are (Abshirini, 2004).

Geography and geology of the study area, including the cities of South Khorasan Cain city that between 33 and 34 degrees north latitude and 38 to 60 degrees east longitude located north of the city KHAF and Yes, with Paradise West and south of the city of Birjand and the East $169 \mathrm{~km}$ border with Afghanistan. Cain plain to access by road and are approximately 105 kilometers south-east Asia Mashhad to Zahedan city Gonabab Cain city located in the western central plains reached. Formation of the plain Cain Precambrian granites, gneisses and metamorphic rocks formed and the formation of the mountains in the south basin Zulmountain is exposed.Mesozoic geological formations that are widespread in the region, the lime "Jurassic and Cretaceous" and alternation of shale and sandstone created. Deposits of Tertiary geology of igneous rocks "ZORASIC, CRETACEOUS" sandstone and conglomerate, and that is evident in the North East and South East Cain plain. 
Quaternary sediments from the terraces, alluvial fans, loess and sand found in plain and mountain range seen this plain.

\section{Procedure}

Telemetry studies of digital elevation data (DEM) of the area to buy and sell segregated lithologic units were used in various combinations of bands and finally the composition according to the previous geological studies conducted (copper exploration area geological studies Vorezg Southeast region, 2007) and the implementation of digital geological map geological survey and mineral exploration for the study area was proposedlithologic. And to determine the fracture density area of spectral filtration method Aster satellite (ASTER) on a scale of 15 and 30 meters were used 1.100000resolution.For layer compression fractures through a combination of band and filtration spectrum by filtering by high pass-angle range more suitable combination various application environments "ENVI" was created and then compared with the geological map1.100000 area map faults Home Region (Report GSI 1355) bands $(7,4,2)$ was the most prominent of them was selected lineaments related fractures. Then fracture and geo-electrical sounding positions always in the software line "ArcGIS9.3" drawn and eventually fracture map marked area on the location of the resulting image was created Gaen. To prepare the topography layer of digital elevation files extracted from satellite images ester (Aster) prepared by the Geological Survey of Iran was used.And by application "3.2 Arcview" were analyzed. And application layer resulting in "Surfer" as the map was derived. For lithologiclayers of different band combinations of polyester was used on the images. And by comparing the geological map of the bands $(2,4,7)$ have the highest resolution of rock units and in combination band $(1,4,7)$ due to the arid areas of Clay and clay minerals was more pronounced. In addition, the composition of the band $(1,3,5)$ also created a suitable resolution. And the combined band $(1,2,3)$ was used to show the unit to a normal color.

The processing of remote sensing and the use of the methods listed, raw satellite images were processed and placed in the form of a map with UTM coordinates. Descriptions of each layer and the effect of a potential underground water in different areas of lowland plains was interpreted Cain

The resulting linear map of the study area (Figure 1), using a spectral filter Highpass was created. Using geological map of the area 1.100000 obtained images was corrected and the major fault and fracture zone were also coincide. Finally, the software "Arc GIS" Map fracture and the area were prepared clauses. The most that can be concluded with regard to: (1) the density of surrounding fractures only to be seen. And the clauses that are typical metropolitan area in the middle of fields that define the city limits on the plains. (2) compression fractures in the eastern part areplainer. That as a key factor for the permeability of underground water in the south and northeast of the city (mainly the eastern border areas of the plains) is considered. (3) Fracture density is relatively low in southern and western plains region. (4) fractures can be caused by subsidence and tectonic plates of Cain successive earthquakes are generated.

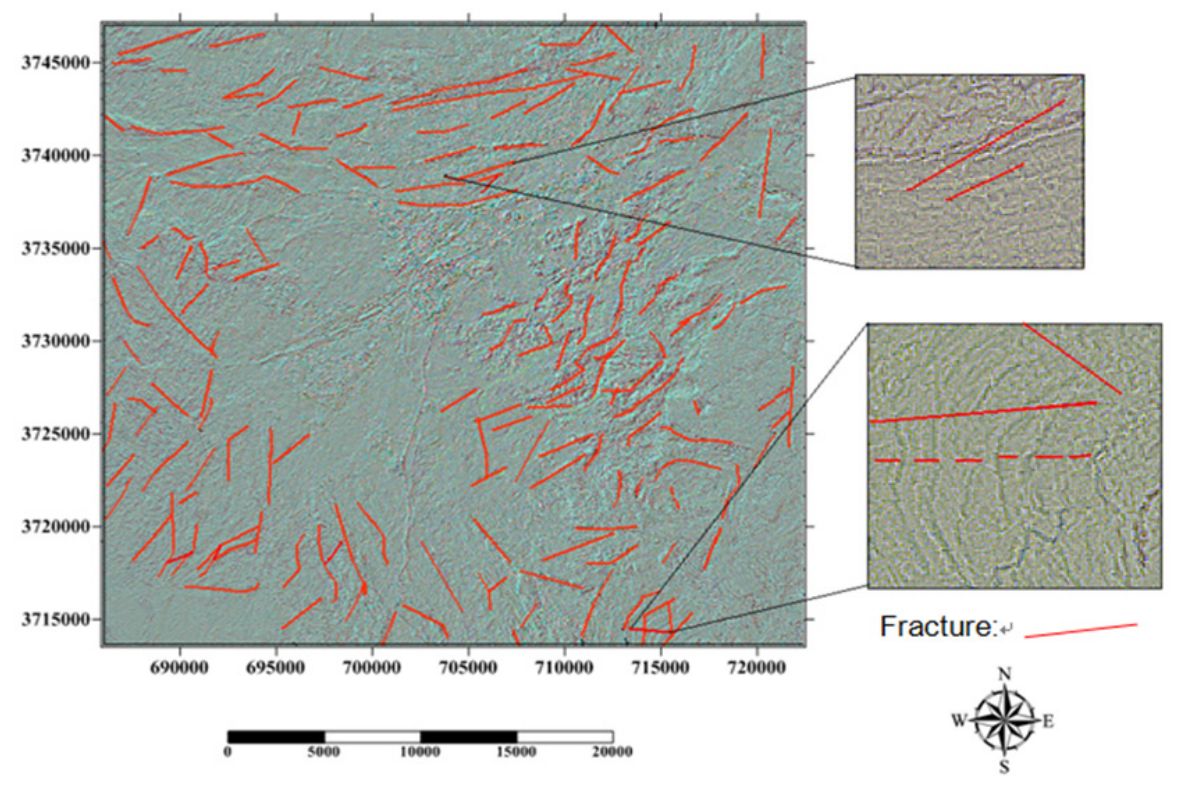

Figure 1. Fractures layer region 
Due to the topography layer map obtained (Figure 2), the height of the zones are sorted. The altitude of 1,250 meters on the area northeast of Cain and maximum height of $2250 \mathrm{~m}$ on east-southwest area is plain. Between 1250 to 1550 meters altitude in the central part of the plain variable. What can be concluded from this layer?

1.Slope and topography in the central part of the interior is plain, especially northeastern plains. 2. Change the slope of the Eastern and Western regions were plainer than the permeability of underground water in these areas is relatively lower assessment 3. In the southeastern part of the Central Plains and the decline is gentler topography tilt Top permeability evaluated 4 . The northern limit is relatively low height which can be considered as input Islamabad plain area, the slope of the ramp in the area of the basin is plain Cain.

According to the foregoing, it can be concluded that the northeast, central and south-eastern plain of the slope and topography has a greater potential for infiltration of surface water and underground aquifers are fed.

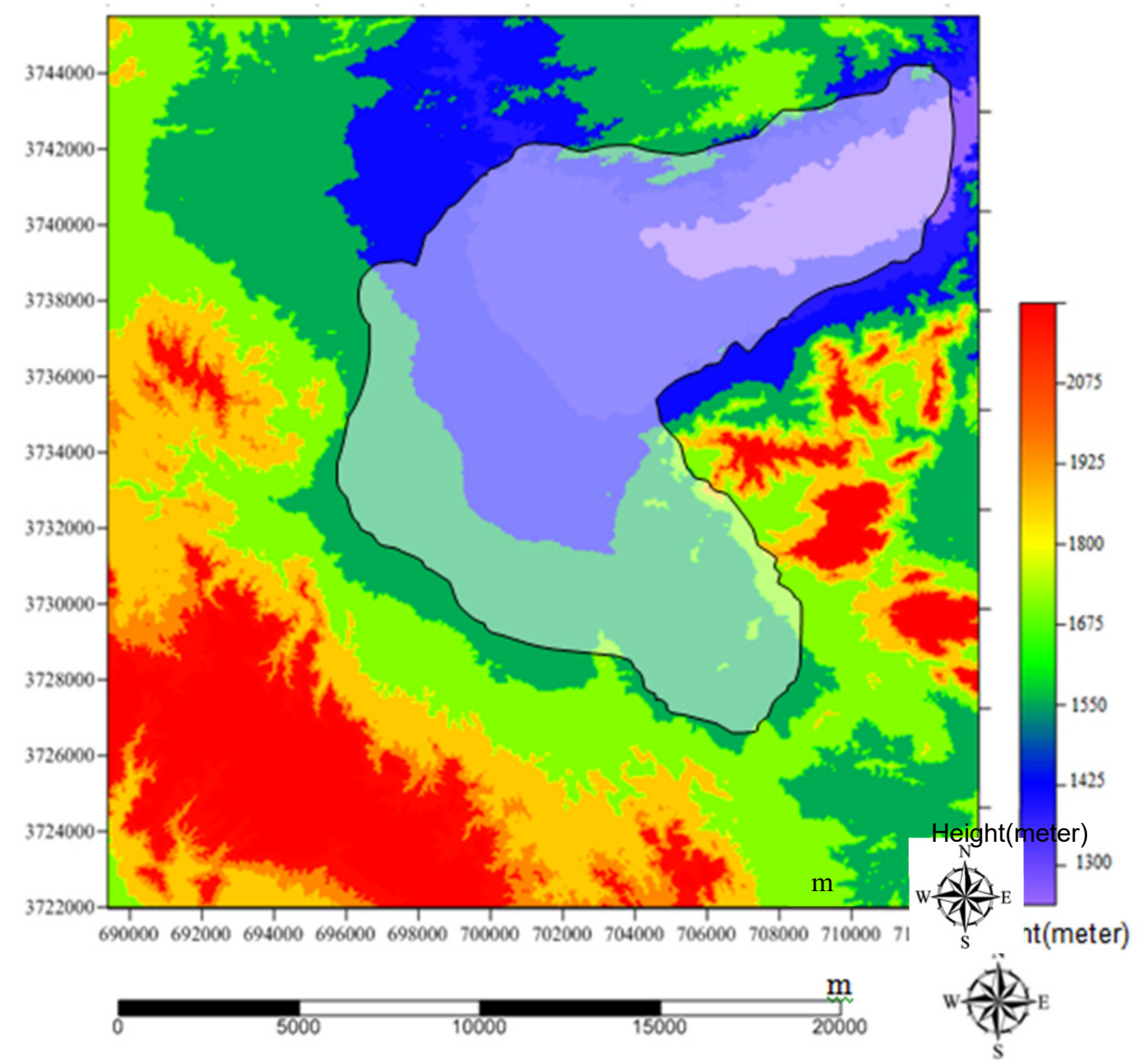

Figure 2. Topography layer region

Lithologic units for separation of different bands combine satellite images were used. And finally, the right combination was selected for study Lithology Bands (band 3 green, 2 blue band, a red band 1) As can be seen, the resulting image (Figure 3 ) is able to distinguish between some of the units as well. For example, Clay light-colored plain can be seen in different areas. Limestone mountains in the eastern plains are well visible. 

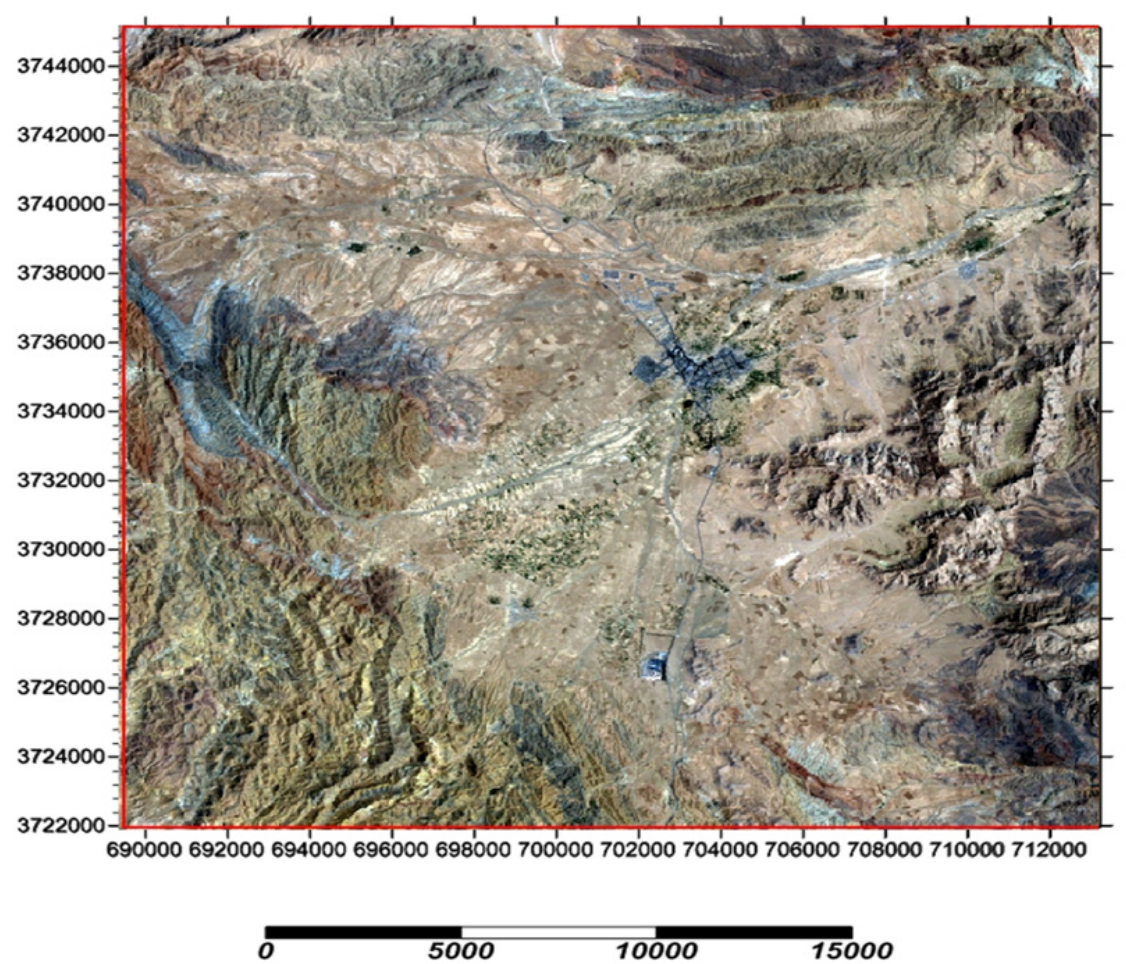

Figure 3. Satellite image composition $(1,2,3)$ of the region

Composition $(5,2,1)$ also had the best color combinations to differentiate band. So that the composition of plants to light green, dark red sandstone unit and limestone regions appear bright red (Figure 4). Volcanic areas are dark blue.

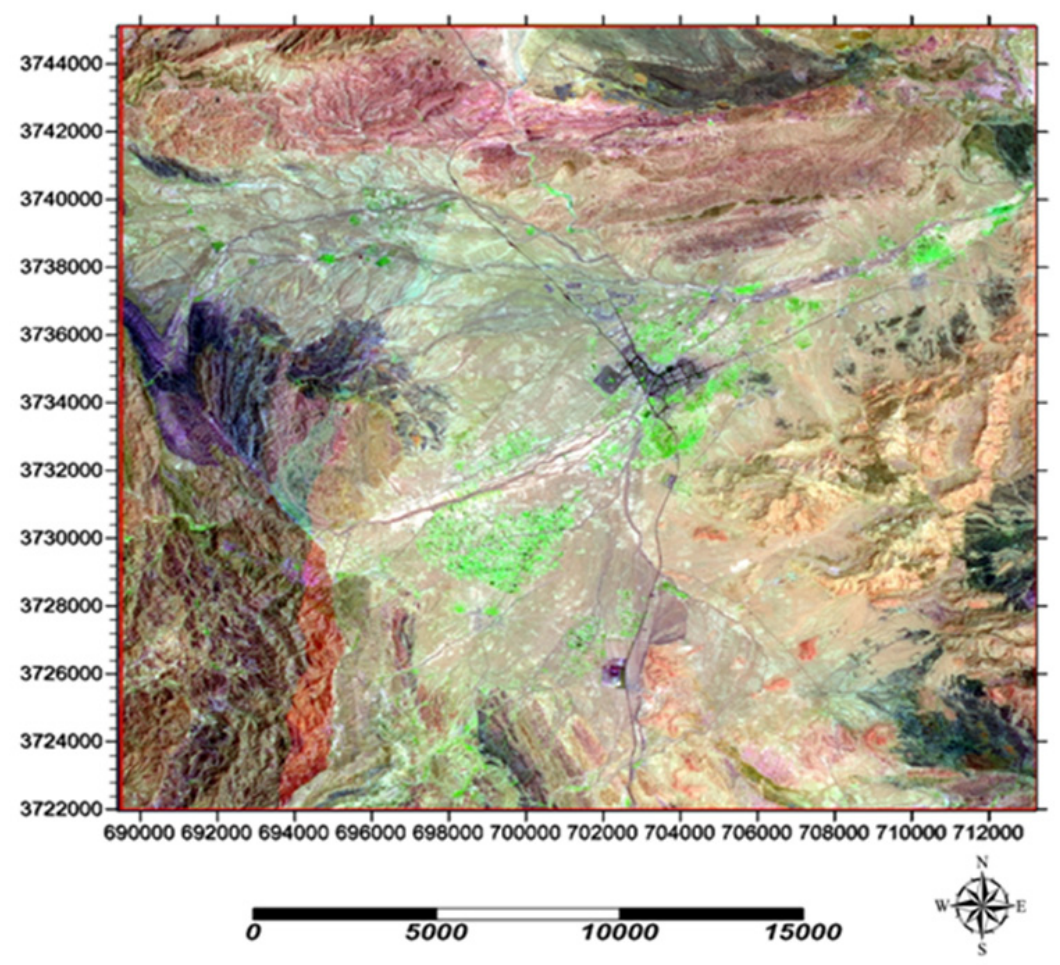

Figure 4. Satellite picture of the composition $(5,2,1)$

Image of composition $(2,4,7)$ compared with the geological map lithology units best color combination for 
further separation of the area (Figure 6). As marked in the central part of the gravel and sand that briefly (gf) in the North West and South West Plains is also evident. In the southern and southeastern desert with Aliumunit (AV) specified (near the village of Mahmooyin) which also have relatively good permeability. But limestone unit (the basin) and volcanic (Andesite units (An) in the north, of granite (Gr) in the South East and basaltic units (Ba) in West Plains) are very low permeability.

In both the northwest and northeast plains also Kanglo units MARAI $(\mathrm{Cm})$ is often seen with calcareous ground in areas that are often lose their low permeability. Crops and agricultural areas (FL) according to their own land drainage to increase permeability, which can be considered as a factor. But based on geological explorations (exploration for copper and other reports Geological Survey) in the eastern area of Cain and are known in the western and northern part of the border mountains are also like: Almond Formation (including shale rock dense limestone and sandstone), make Baghamshah (mostly thick sediments Chile) and Jamal Formation (including the thick limestone layer dolomite) and this castle (including shale and limestone Cinq thick and protrusions) suitable for penetration and exploration not assessed.

But the central plain area of the Quaternary GranodioriteAlium rock and gravel (According to the Central Plains to the coarse sand to a depth of 30 meters should) have a good potential to penetrate Pzyy, moreover in these areas are related to the Pliocene deposits, which more or less cement loose sediments and medium permeability. Finally, it can be concluded that in the eastern plains and deep deposits of the Central Plains Kovarterrny permeability due to alternate layers of coarse sand and the potential influence of surface water Suitable are being assessed.

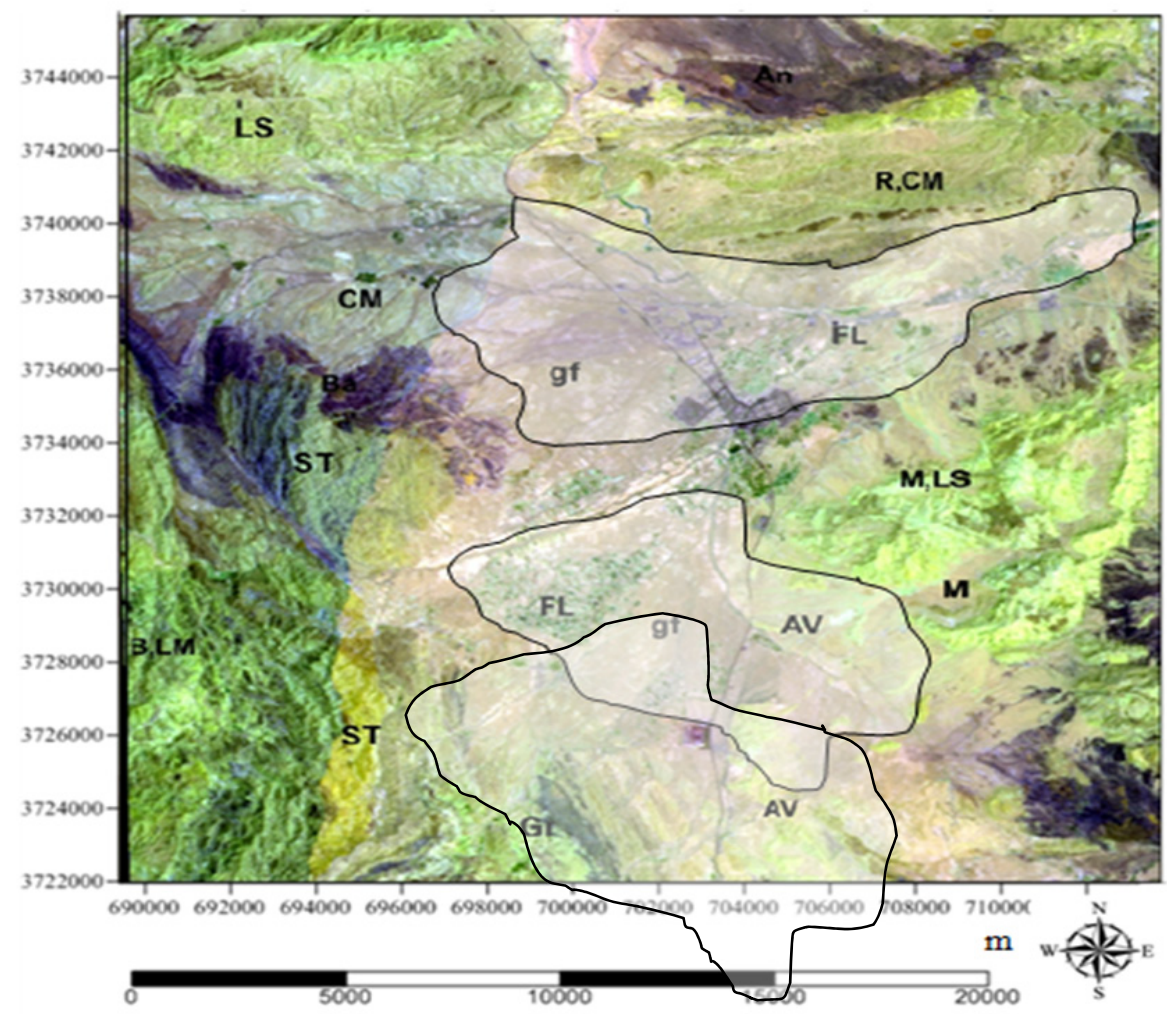

Figure 5. Satellite image composition $(2,4,7)$

\section{Conclusion}

The interpretation of remote sensing data acquisition areas for potential groundwater was determined for each layer. Principles finding underground water potential in cases where the number of layers increases and a large sprawl of the proposed areas are usually based on weight. However, given that in this area the importance of thegeological layershave been examined, as resulting number of layers arelimitedto three layers (fractures, topography, lithology)The combination of less scattering layer and only certain areas by the overlap can be 
studied in the previous chapter. As shown in Figure (8-1) of the layers can be seen: the plains of eastern and southern areas of greatest overlap and are worth exploring, but the central and western plains have the least overlap and in the next ranks reviews fall exploration and discovery are often worthless.

\section{References}

Abshirini, \& Rngzn, K. (2004). The application of remote sensing and GIS techniques to identify and locate potential underground water resources in the anticline Pabndeh efficient. Shahid Chamran University.

Adeli, M., \& Ziaeian, C. (2010). Seeking potential groundwater by GIS and Remote Sensing Case Study: city of Gorgan. Geomatics Conference and Exhibition, Tehran.

Ali, P., \& Khodaee, A. (2003). Survey of water resources and water level in the Lut desert Clute earth using satellite data. Geographic Journal.

Khodaee, A. (2000). Represents the role of groundwater in karst detection of Urmia basin by using GIS. Master's thesis, ShahidBeheshti University in Tehran.

Safe, A. A., \& Kargar, A. (2011). Finding potential ground water using hierarchical analysis and GIS system. Sirjan water shedcase study.

\section{Copyrights}

Copyright for this article is retained by the author(s), with first publication rights granted to the journal.

This is an open-access article distributed under the terms and conditions of the Creative Commons Attribution license (http://creativecommons.org/licenses/by/3.0/). 